J. Lake Sci.(湖泊科学), 2019, 31(4): 969-975

DOI 10. 18307/2019. 0424

(c) 2019 by Journal of Lake Sciences

\title{
乌梁素海盐分在冰一水一沉积物间的分布及迁移特征”
}

\author{
姜 涛, 张 生**,赵胜男, 史小红,孙 标,刘 禹,田伟东,杜丹丹
}

(内蒙古农业大学水利与土木建筑工程学院, 呼和浩特 010018)

\begin{abstract}
摘 要: 盐分是参与湖泊物质循环的重要成分之一, 湖泊盐度增加对湖泊生态系统健康造成了严重的威胁. 乌梁素海总 溶解性固体 (TDS) 和盐度均处于较高的水平, 为揭示盐分在冰一水一沉积物中的分布及迁移规律, 冰封期在乌梁素海 7 个 采样点采集冰、冰下水和不同深度沉积物样品, 分析样品的 TDS、 $\mathrm{Na}^{+}$和 $\mathrm{Cl}^{-}$浓度, 得到各自在冰一水间浓度的比值, 即分配 系数 $K$, 并对水一沉积物界面 $\mathrm{Na}^{+}$和 $\mathrm{Cl}^{-}$的扩散通量进行估算. 结果显示, TDS、 $\mathrm{Na}^{+}$和 $\mathrm{Cl}^{-}$在冰一水中分配系数 $K$ 的均值分 别为 $0.02 、 0.03$ 和 0.01 , 表明在湖水结冰形成冰盖的过程中, 随着冰晶的析出, TDS、 $\mathrm{Na}^{+}$和 $\mathrm{Cl}^{-}$逐渐在水体中浓缩, 水体中 $\mathrm{Na}^{+}$和 $\mathrm{Cl}^{-}$在浓度梯度驱动力作用下, 向沉积物间隙水中扩散, 估算其扩散通量均值分别为 -229 和 $-676 \mathrm{mg} /\left(\mathrm{m}^{2} \cdot \mathrm{d}\right)$. 总 之, 湖水在冻结过程中, 由于冰晶的析出, 盐分向冰下水体中迁移, 使得盐分浓度在冰下水体中浓缩增加, 继而向沉积物 中迁移,对湖泊水生态环境构成胁迫.
\end{abstract}

关键词: 冰封期; 乌梁素海;盐分;分布;迁移;扩散通量

\section{Distribution and migration characteristics of salinity in ice-water-sediment in Lake Ulansuhai}

JIANG Tao, ZHANG Sheng ${ }^{* *}$, ZHAO Shengnan, SHI Xiaohong, SUN Biao, LIU Yu, TIAN Weidong \& DU Dandan

(Water Conservancy and Civil Engineering College, Inner Mongolia Agricultural University, Hohhot 010018, P.R.China)

Abstract: Salinity is an important substances involved in the material cycle of lakes. Salinity increase in lakes poses a serious threat to the health of lake ecosystems. Lake Ulansuhai is one of the eight largest freshwater lakes in China, the largest lake in the Yellow River Basin, and also a typical shallow grassland lake in the cold and arid zone in Inner Mongolia. The lake water usually starts freezing in the early November and thawing in the end of March or in the early April of the following year. Total dissolved solids (TDS) and salinity in the lake have been increasing gradually and are at a high level at present. In order to reveal the distribution and migration characteristics of the TDS and salinity in the ice-water-sediment interface, samples of the ice, water, and sediments at different depths were collected at seven sampling sites during the ice-sealing period. The concentrations of TDS, $\mathrm{Na}^{+}$and $\mathrm{Cl}^{-}$ were analyzed. The distribution coefficient $(K)$ of TDS, $\mathrm{Na}^{+}$and $\mathrm{Cl}^{-}$between the ice and water were analyzed. The diffusion fluxes of $\mathrm{Na}^{+}$and $\mathrm{Cl}^{-}$between the water-sediment interfaces were estimated. The results showed that the mean $K$ of TDS, $\mathrm{Na}^{+}$, and $\mathrm{Cl}^{-}$ were $0.02,0.03$ and 0.01 , respectively. This indicated that the salinity was gradually concentrated in the water body during the process of ice crystal precipitation. As a result, the salinity would be further transported into sediment due to the concentration gradient between the water-sediment interfaces. The estimated mean diffusion fluxes of $\mathrm{Na}^{+}$and $\mathrm{Cl}^{-}$between the water-sediment interfaces were $-229 \mathrm{mg} /\left(\mathrm{m}^{2} \cdot \mathrm{d}\right)$ and $-676 \mathrm{mg} /\left(\mathrm{m}^{2} \cdot \mathrm{d}\right)$, respectively. In short, during the lake's freezing process, the salinity migrated to the liquid phase due to the precipitation of ice crystals. The concentration of salinity in the water body increased gradually and then migrated into sediment. This would constitute a stress on the lake's ecological environment.

Keywords: Ice-sealing period; Lake Ulansuhai; salinity; distribution; migration; diffusion fluxes

近年来由于气候变暖和人类活动的双重影响, 对湖泊生态系统的健康造成了严重的威胁, 湖泊盐度增

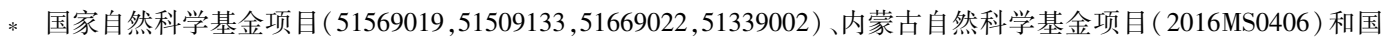
家重点基础研究发展计划 (2017YFE0114800) 联合资助. 2018-10-09 收稿;2019-01-10 收修改稿. 姜涛( 1993 ), 女,硕士研究生;E-mail: 2697910344@qq.com.

** 通信作者; E-mail: shengzhang@imau.edu.cn. 
加是其中面临的生态环境问题之一 ${ }^{[1-2]}$. 总溶解性固体 (TDS) 是指在水中溶解的各类有机物或无机物的总 称. 其主要成分有钾离子、钙离子、钠离子、镁离子、碳酸根离子、碳酸氢根离子、硝酸根离子和氯离子. 由于 乌梁素海湖泊地处半干旱地区, 该区域降水稀少、地表径流补给不丰、蒸发强度超过湖水的补给量 ${ }^{[3]}$, 因此 TDS 浓度高是该区域湖泊最主要的污染特征 ${ }^{[4.5]}$. 乌梁素海湖水中 TDS 的主要成分是 $\mathrm{Na}^{+}$和 $\mathrm{Cl}^{-[6]}$, 湖泊水体 属于 $[\mathrm{Cl}] \mathrm{Na}$ III 型水 ${ }^{[7]}$. 天然湖泊中, $\mathrm{Na}^{+}$和 $\mathrm{Cl}^{-}$主要来源于岩石的风化、溶解以及火山喷发. 然而随着工农业 的发展, 大量废水排人湖泊, 造成湖泊环境发生一系列变化, 水体中 $\mathrm{Na}^{+}$和 $\mathrm{Cl}^{-}$浓度增加, 加剧湖泊的盐化程 度, 进而影响鱼类等生长, 阻碍渔业的发展 ${ }^{[8]}$.

乌梁素海冰封期时间较长, 冰冻厚度较大, 根据冷冻浓缩原理, 在湖水结冰过程中, 随着冰晶的析出, 污 染物逐渐在冰下水体中浓缩, 甚至累积于湖底沉积物中, 加重来年非冰封期湖泊内源污染 ${ }^{[9]}$. 由于自然结冰 温度的变化及不同溶质的平衡温度有所差异等因素的影响, 污染物在冰体中会有不同程度的残留. 沉积物 是各种污染物及其相互作用的载体, 既可作为污染物的 “源” 通过扩散作用向上覆水体中释放污染物, 又可 作为污染物的 “汇” 富集水体中的污染物 ${ }^{[10]}$. 水一沉积物界面是环境中水体和沉积物之间的转换 ${ }^{[11]}$, 沉积 物间隙水是水一沉积物界面中物质交换的主要媒介, 沉积物孔隙是上覆水体和沉积物之间进行物质交换的 重要场所 ${ }^{[12]}$. 揭示冰封期乌梁素海冰一水、水一沉积物界面盐分的分布特征和迁移特征, 有助于更好地认识 乌梁素海的水环境变化过程.

本文以乌梁素海为研究对象, 测定了冰封期冰体、水体与沉积物的理化性质, 分析冰体、水体与沉积物 间隙水中 TDS、 $\mathrm{Na}^{+}$和 $\mathrm{Cl}^{-}$量, 利用 Fick 第一定律估算了水一沉积物界面 $\mathrm{Na}^{+}$和 $\mathrm{Cl}^{-}$的扩散通量, 明确盐分在 冰一水、水一沉积物界面的迁移过程, 以期为冰封期湖泊化学环境变化的研究及盐化治理提供数据支撑和科 学依据.

\section{1 材料与方法}

\section{1 研究区概况}

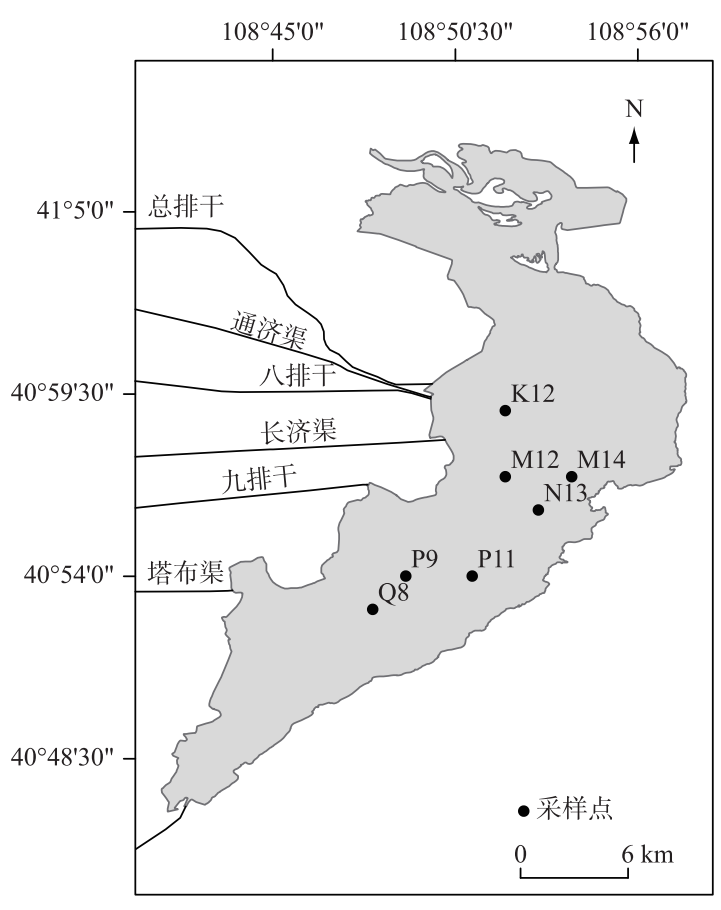

乌梁素海 $\left(40^{\circ} 36^{\prime} \sim 41^{\circ} 03^{\prime} \mathrm{N}, 108^{\circ} 43^{\prime} \sim 108^{\circ} 57^{\prime}\right.$ E) 位于内蒙古巴彦淖尔市乌拉特前旗境内, 中国 八大淡水湖之一, 是黄河流域最大的湖泊,也是内 蒙古高原干旱区最典型的浅水草型湖泊. 湖区是 南北走向, 北宽南窄, 湖面平均高程为 $1018.5 \mathrm{~m}$. 多年平均降水量为 $224 \mathrm{~mm}$, 多年平均蒸发量为 $1502 \mathrm{~mm}$. 多年平均气温为 $7.3^{\circ} \mathrm{C}$,一般从每年 11 月初进人冰封期, 到次年 3 月末至 4 月初开始融 化, 约有 4 5 个月处于冰层覆盖阶段, 冰封期长达 $100 \sim 130 \mathrm{~d}$, 累积负积温为 $610 \sim 800^{\circ} \mathrm{C} \cdot \mathrm{d}$, 多年冰 盖平均厚度为 $0.63 \mathrm{~m}^{[9]}$.

\section{2 样品的采集}

综合考虑安全性、可操作性、取样的难易程度 及乌梁素海的水动力学特征, 于 2018 年 2 月 1 日 在乌梁素海湖区的 7 个采样点进行冰样、水样和 沉积物的采集工作 (图 1). 冰样采用自制冰芯取 样器 (专利号:ZL201120253762.4) 采集, 水样采用 自制多功能采水器 (专利号: ZL201020680966.1) 采集, 沉积物采用自制的真空柱状取泥器进行采 集. 采集冰一水界面以上 $10 \mathrm{~cm}$ 厚度冰样 1 层, 在 图 1 乌梁素海采样点分布

Fig.1 Distribution of sampling sites in Lake Ulansuhai 每个采样点 $5 \mathrm{~cm}$ 深度上采集水样 1 层, 沉积物采 集深度为 $25 \mathrm{~cm}$, 每 $5 \mathrm{~cm}$ 作为 1 个样层, 共采集 5 
层. 冰样于常温避光融化后测定, 水样置于 $4^{\circ} \mathrm{C}$ 保温箱中保存, $24 \mathrm{~h}$ 内将分割后的沉积物样品以 4000 转 $/ \mathrm{min}$ 离心 $20 \mathrm{~min}$, 取上清液过 $0.45 \mu \mathrm{m}$ 滤膜得到沉积物间隙水. TDS 和 $\mathrm{Na}^{+} 、 \mathrm{Cl}^{-}$分别用 TDS 测试笔 (EUTECH, TDS Testrl0 low + ) 和美国戴安 (DIONEX) 公司生产的 ICS-90 离子色谱仪检测.

\section{3 研究方法}

冰一水分配系数指溶质在冰水两相中的浓度比值, 它可反映溶质在冰晶析出过程中, 冰水两相中溶质的 浓度关系. 可以表征在水体结冰过程中不同物质由冰体向水体的排出效应. 定义分配系数为 ${ }^{[6]}$ :

$$
K=C_{\mathrm{S}} / C_{\mathrm{L}}
$$

式中, $C_{\mathrm{s}}$ 为冰中溶质浓度 $(\mathrm{mg} / \mathrm{L}), C_{\mathrm{L}}$ 为冰下水中溶质浓度 $(\mathrm{mg} / \mathrm{L})$.

由浓度梯度所引起的分子扩散作用是上覆湖水与沉积物之间进行溶质交换的主要形式. 假设在水一沉 积物界面附近某溶质在水体和沉积物中的浓度不随时间变化, 即该溶质在水一沉积物间处于稳定扩散状态, 其净通量可用 Fick 第一定理进行估算 ${ }^{[13-14]}$, 扩散通量表达式为:

$$
F=-\varphi \cdot D_{\mathrm{s}} \cdot \mathrm{d} c / \mathrm{d} x
$$

式中, $F$ 为通过沉积物一水界面的扩散通量 $\left(\mathrm{mg} /\left(\mathrm{m}^{2} \cdot \mathrm{d}\right)\right) ; \varphi$ 为沉积物孔隙度, 通过沉积物饱和含水率推 算 ${ }^{[15]} ; \mathrm{d} c / \mathrm{d} x$ 为沉积物一水界面间隙水中溶质的浓度梯度 $(\mathrm{mg} /(\mathrm{L} \cdot \mathrm{cm})) ; D_{\mathrm{s}}$ 为溶质的扩散系数 $\left(\mathrm{m}^{2} / \mathrm{s}\right)$. 通常 当 $\varphi \leqslant 0.7$ 时, $D_{\mathrm{s}}=\varphi \cdot D_{0}$; 当 $\varphi>0.7$ 时, $D_{\mathrm{s}}=\varphi^{2} \cdot D_{0}{ }^{[16]} ; D_{0}$ 为理想溶液中溶质的扩散系数 $\left(\mathrm{m}^{2} / \mathrm{s}\right)$. 根据 $\varphi$ 和 $D_{0}{ }^{[17]}$, 结合间隙水剖面分析,由公式 (2) 可以计算出扩散通量.

\section{2 结果}

\section{1 盐分在冰一水中的迁移特征}

表 1 为乌梁素海盐分在冰一水中的分配系数. 乌梁素海 TDS、 $\mathrm{Na}^{+}$和 $\mathrm{Cl}^{-}$在冰体中 $C_{\mathrm{s}}$ 浓度变化范围分别 为 $31.2 \sim 81.9 、 11.4 \sim 28.9$ 和 $8.0 \sim 14.6 \mathrm{mg} / \mathrm{L}$, 均值分别为 $45.3 、 20.4$ 和 $10.6 \mathrm{mg} / \mathrm{L}$; 在冰下水体中 $C_{\mathrm{L}}$ 浓度变化 范围分别为 2228 3297、557 764 和 901 1159 mg/L, 均值分别为 $2488 、 651$ 和 $1020 \mathrm{mg} / \mathrm{L}$, 即冰下水体浓度 分别为冰体中浓度的 $55 、 32$ 和 96 倍, TDS、 $\mathrm{Na}^{+}$和 $\mathrm{Cl}^{-}$在冰一水中的分配系数均值分别为 $0.02 、 0.03$ 和 0.01 (表 1). 表明乌梁素海湖水中 TDS、 $\mathrm{Na}^{+}$和 $\mathrm{Cl}^{-}$在水体结冰过程中, 由于冰晶的析出使绝大部分溶质在冰下水 体中浓缩.

表 1 乌梁素海盐分在冰一水中的分配系数

\begin{tabular}{|c|c|c|c|c|c|c|c|c|c|}
\hline \multirow{2}{*}{ 采样点 } & \multicolumn{3}{|c|}{ TDS } & \multicolumn{3}{|c|}{$\mathrm{Na}^{+}$} & \multicolumn{3}{|c|}{$\mathrm{Cl}^{-}$} \\
\hline & $C_{\mathrm{S}} /(\mathrm{mg} / \mathrm{L})$ & $C_{\mathrm{L}} /(\mathrm{mg} / \mathrm{L})$ & K & $C_{\mathrm{S}} /(\mathrm{mg} / \mathrm{L})$ & $C_{\mathrm{L}} /(\mathrm{mg} / \mathrm{L})$ & K & $C_{\mathrm{S}} /(\mathrm{mg} / \mathrm{L})$ & $C_{\mathrm{L}} /(\mathrm{mg} / \mathrm{L})$ & K \\
\hline K12 & 81.9 & 2619 & 0.03 & 11.4 & 723 & 0.02 & 9.5 & 1159 & 0.01 \\
\hline M12 & 47.7 & 3297 & 0.01 & 20.7 & 748 & 0.03 & 11.2 & 1031 & 0.01 \\
\hline M14 & 35.8 & 2326 & 0.02 & 22.6 & 764 & 0.03 & 8.0 & 1122 & 0.01 \\
\hline N13 & 31.2 & 2228 & 0.01 & 18.7 & 617 & 0.03 & 10.5 & 966 & 0.01 \\
\hline P9 & 50.1 & 2326 & 0.02 & 28.9 & 557 & 0.05 & 14.6 & 910 & 0.02 \\
\hline P11 & 38.4 & 2326 & 0.02 & 24.1 & 580 & 0.04 & 11.3 & 901 & 0.01 \\
\hline Q8 & 32.3 & 2294 & 0.01 & 16.7 & 564 & 0.03 & 8.7 & 1049 & 0.01 \\
\hline 均值 & 45.3 & 2488 & 0.02 & 20.4 & 651 & 0.03 & 10.6 & 1020 & 0.01 \\
\hline
\end{tabular}

Tab.1 Distribution coefficient of salinity at ice-water interface in Lake Ulansuhai

\section{2 盐分在水一沉积物界面的剖面特征}

水一沉积物界面是物质传输的重要交换媒介, 分析湖泊沉积物间隙水盐分浓度的垂向分布特征对于深 人了解盐分在水体与沉积物之间的交换机制具有一定的帮助. 乌梁素海水一沉积物界面 TDS、 $\mathrm{Na}^{+}$和 $\mathrm{Cl}^{-}$的垂 直剖面特征可知, 水一沉积物界面处上覆水体中 TDS 浓度变化范围为 $2228 \sim 3297 \mathrm{mg} / \mathrm{L}$, 平均值为 2248 $\mathrm{mg} / \mathrm{L}$. 水中 TDS 浓度高于沉积物间隙水中 TDS 浓度, 间隙水中 TDS 浓度均值为 $1578 \mathrm{mg} / \mathrm{L}$, 即水体中 TDS 浓度是间隙水的 1.4 倍. 表层沉积物 $(0 \sim 5 \mathrm{~cm})$ 间隙水是水一沉积物界面间盐分传输的重要交换介质. 大部 
分采样点的 $0 \sim 5 \mathrm{~cm}$ 表层沉积物间隙水中 TDS 浓度要小于上覆水体中 TDS 浓度, 其变化范围在 1014 2730 $\mathrm{mg} / \mathrm{L}$, 平均值为 $1695 \mathrm{mg} / \mathrm{L}$. 从垂向分布情况上看, M12 点、M14 点和 P11 点沉积物间隙水中 TDS 浓度的最 高值均出现在表层 $0 \sim 5 \mathrm{~cm}, \mathrm{~K} 12$ 点沉积物间隙水中 TDS 浓度的最高值出现在 5 10 $\mathrm{cm}$ 深度处, P9 点间隙 水中 TDS 浓度最高值出现在深度 $10 \sim 15 \mathrm{~cm}$ 处, Q8 点间隙水中 TDS 浓度最高值出现在深度 $15 \sim 20 \mathrm{~cm}$ 处, N13 点间隙水中 TDS 浓度最高值出现在 $20 \sim 25 \mathrm{~cm}$ 深度处(图 2).
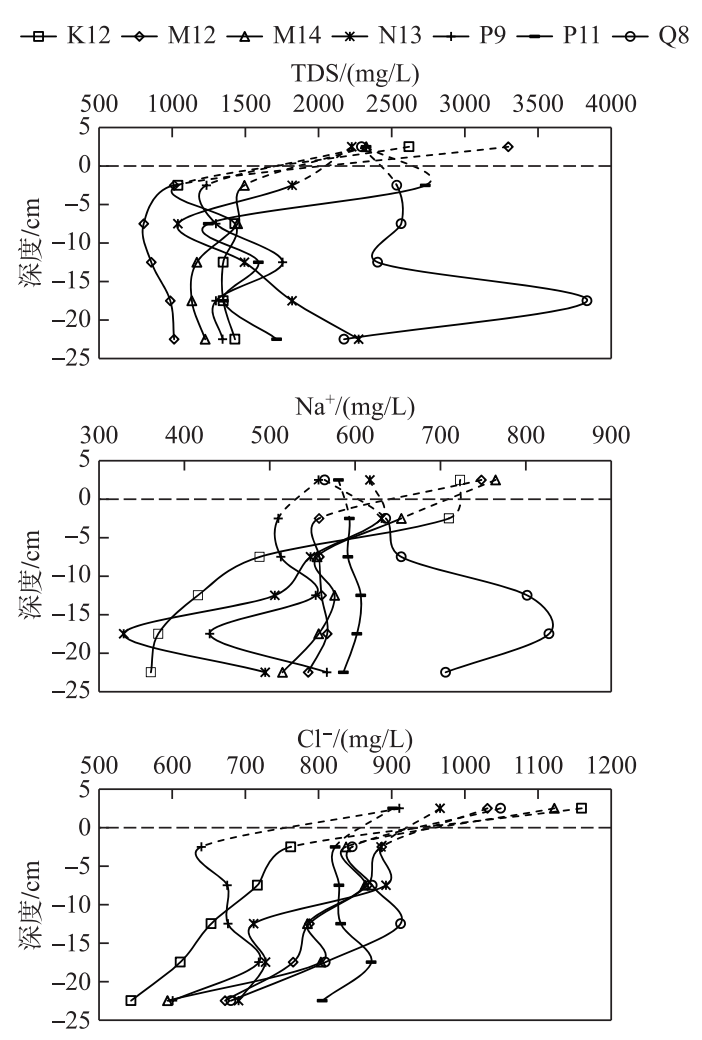

图 2 乌梁素海各采样点水体和沉积物 不同深度 TDS、 $\mathrm{Na}^{+}$和 $\mathrm{Cl}^{-}$浓度

Fig. 2 Concentrations of TDS, $\mathrm{Na}^{+}$and $\mathrm{Cl}^{-}$ in the water body and the sediment at different depths of each site in Lake Ulansuhai

水一沉积物界面处上覆水体中 $\mathrm{Na}^{+}$浓度变化范 围为 $557 \sim 764 \mathrm{mg} / \mathrm{L}$, 平均值为 $651 \mathrm{mg} / \mathrm{L}$. 水中 $\mathrm{Na}^{+}$ 浓度高于沉积物间隙水中 $\mathrm{Na}^{+}$浓度, 间隙水中 $\mathrm{Na}^{+}$浓 度均值是 $568 \mathrm{mg} / \mathrm{L}$, 即水体中 $\mathrm{Na}^{+}{ }^{+}$浓度是间隙水的 1.1 倍. 大部分采样点的 $0 \sim 5 \mathrm{~cm}$ 表层沉积物间隙水 中 $\mathrm{Na}^{+}$浓度要小于上覆水体中 $\mathrm{Na}^{+}$浓度, 其变化范围 在 $509 \sim 710 \mathrm{mg} / \mathrm{L}$, 平均值为 $613 \mathrm{mg} / \mathrm{L}$. 从垂向分布 情况上看, K12 点、M14 点和 N13 点沉积物间隙水中 $\mathrm{Na}^{+}$浓度最高值均出现在表层 $0 \sim 5 \mathrm{~cm}, \mathrm{P} 11$ 点沉积 物间隙水中 $\mathrm{Na}^{+}$浓度的最高值出现在 $10 \sim 15 \mathrm{~cm}$ 深 度处, M12 点和 Q8 点间隙水中 $\mathrm{Na}^{+}$浓度最高值出现 在 $15 \sim 20 \mathrm{~cm}$ 深度处, $\mathrm{P} 9$ 点间隙水中 $\mathrm{Na}^{+}$浓度最高 值出现在 $20 \sim 25 \mathrm{~cm}$ 深度处 (图 2).

水一沉积物界面处上覆水体中 $\mathrm{Cl}^{-}$浓度变化范 围为 $901 \sim 1159 \mathrm{mg} / \mathrm{L}$, 平均值为 $1020 \mathrm{mg} / \mathrm{L}$. 水中 $\mathrm{Cl}^{-}$ 浓度高于沉积物间隙水中 $\mathrm{Cl}^{-}$浓度, 间隙水中 $\mathrm{Cl}^{-}$浓 度的均值是 $772 \mathrm{mg} / \mathrm{L}$, 即水体中 $\mathrm{Cl}^{-}$浓度是间隙水的 1.3 倍. 大部分采样点的 $0 \sim 5 \mathrm{~cm}$ 表层沉积物间隙水 中 $\mathrm{Cl}^{-}$浓度要小于上覆水体中 $\mathrm{Cl}^{-}$浓度, 其变化范围 为 $640 \sim 886 \mathrm{mg} / \mathrm{L}$, 平均值为 $811 \mathrm{mg} / \mathrm{L}$. 从垂向分布 情况上看, $\mathrm{K} 12$ 点和 $\mathrm{M} 12$ 点沉积物间隙水中 $\mathrm{Cl}^{-}$浓度 的最高值均出现在表层 $0 \sim 5 \mathrm{~cm}, \mathrm{M} 14$ 点和 N13 点沉 积物间隙水中 $\mathrm{Cl}^{-}$浓度的最高值均出现在 $5 \sim 10 \mathrm{~cm}$ 深度处, $\mathrm{Q} 8$ 点间隙水中 $\mathrm{Cl}^{-}$浓度最高值出现在 $10 \sim$ $15 \mathrm{~cm}$ 深度处, $\mathrm{P} 9$ 点和 $\mathrm{P} 11$ 点间隙水中 $\mathrm{Cl}^{-}$浓度最高 值出现在 15 20 cm 深度处 (图 2). 由于受沉积环 境、沉积物形状早期成岩作用及人类活动等的影 响 ${ }^{[18]}$, 不同采样点 TDS、 $\mathrm{Na}^{+}$和 $\mathrm{Cl}^{-}$垂向变化有所差

异,但总体表现出随深度增加浓度降低的趋势.

\section{3 盐分在水一沉积物界面的扩散通量}

水一沉积物界面物质进行交换的过程主要包括对流通量和扩散通量,一般在流速较低的情况下, 对流通 量远远小于扩散通量, 物质的迁移过程主要是由界面上下的浓度梯度所引起的扩散转移过程所主导, 物质 的分布主要受一维垂向迁移和反应过程控制. 乌梁素海总体上在冰封期冰下水体中 $\mathrm{Na}^{+}$和 $\mathrm{Cl}^{-}$是一个浓缩过 程, 水体仅一次采样且采样是在近乎湖冰达到最厚时进行的, 无法追溯水体和沉积物中 $\mathrm{Na}^{+}$和 $\mathrm{Cl}^{-}$浓度在时 空上的变化过程. 这里假设水体和沉积物中 $\mathrm{Na}^{+}$和 $\mathrm{Cl}^{-}$在水一沉积物界面附近的浓度为常数, 不随时间变化, 即水一沉积物界面处溶质为稳定扩散状态, 并忽略 $\mathrm{Na}^{+}$和 $\mathrm{Cl}^{-}$的物理和化学反应, 用 Fick 第一定律估算水一 沉积物界面处溶质迁移通量. 间隙水中溶质含量通常对深度的变化服从指数分布规律, 因此, 将间隙水上端 扰动层 $\left(0 \sim 10 \mathrm{~cm}\right.$ ) 以及界面上覆水 $0 \sim 5 \mathrm{~cm}$ 处的 $\mathrm{Na}^{+}$和 $\mathrm{Cl}^{-}$浓度 $(y)$ 对深度 $(x)$ 进行指数拟合 (拟合曲线) (表 2). 从上覆水体与间隙水 $\mathrm{Na}^{+}$和 $\mathrm{Cl}^{-}$浓度对深度的指数拟合的结果看, $R^{2}$ 介于 $0.617 \sim 1.000$ 之间, 乌梁素海各 
采样点的相关系数都较高. 采样点所在区域 $\mathrm{Na}^{+}$的扩散通量既有正值出现, 又有负值出现, 总体上 $\mathrm{Na}^{+}$的扩 散通量为负值; $\mathrm{Cl}^{-}$的扩散通量均为负值. 表明 $\mathrm{Na}^{+}$和 $\mathrm{Cl}^{-}$从上覆水体向沉积物间隙水扩散, 而且吸附现象明 显. $\mathrm{Na}^{+}$扩散通量 $F$ 的均值为 $-229 \mathrm{mg} /\left(\mathrm{m}^{2} \cdot \mathrm{d}\right)$, 其中, $\mathrm{K} 12$ 点扩散速率最高, 达到 $-746 \mathrm{mg} /\left(\mathrm{m}^{2} \cdot \mathrm{d}\right)$; 其次为 M12 和 M14 点, 扩散速率分别为 -422 和 $-388 \mathrm{mg} /\left(\mathrm{m}^{2} \cdot \mathrm{d}\right) ; \mathrm{P} 11$ 点的扩散速率较低, 为 $23 \mathrm{mg} /\left(\mathrm{m}^{2} \cdot \mathrm{d}\right)$. $\mathrm{Cl}^{-}$扩 散通量 $F$ 的均值为 $-676 \mathrm{mg} /\left(\mathrm{m}^{2} \cdot \mathrm{d}\right)$, 其中, $\mathrm{K} 12$ 点扩散速率最高, 达到 $-2198 \mathrm{mg} /\left(\mathrm{m}^{2} \cdot \mathrm{d}\right)$; 其次为 M14 和 M12 点, 扩散速率分别为 -690 和 $-534 \mathrm{mg} /\left(\mathrm{m}^{2} \cdot \mathrm{d}\right) ; \mathrm{N} 13$ 点的扩散速率较低, 为 $-177 \mathrm{mg} /\left(\mathrm{m}^{2} \cdot \mathrm{d}\right)$. 根据全湖 不同采样点的实测数据, 经过 Fick 定律计算得到的乌梁素海 $\mathrm{Na}^{+}$和 $\mathrm{Cl}^{-}$的界面迁移速率见表 2 .

表 2 水一沉积物界面 $\mathrm{Na}^{+}$和 $\mathrm{Cl}^{-}$扩散通量 ${ }^{*}$

Tab.2 Diffusion flux of $\mathrm{Na}^{+}$and $\mathrm{Cl}^{-}$at the water-sediment interface

\begin{tabular}{|c|c|c|c|c|c|c|c|c|}
\hline 盐分 & 采样点 & 拟合曲线 & $R^{2}$ & $\mathrm{~d} c / \mathrm{d} x$ & $\varphi$ & $\begin{array}{c}D_{0} / \\
\left(\times 10^{-6} \mathrm{~cm}^{2} / \mathrm{s}\right) \\
\end{array}$ & $\begin{array}{c}D_{\mathrm{s}} / \\
\left(\times 10^{-6} \mathrm{~cm}^{2} / \mathrm{s}\right) \\
\end{array}$ & $\begin{array}{c}F / \\
\left(\mathrm{mg} /\left(\mathrm{m}^{2} \cdot \mathrm{d}\right)\right.\end{array}$ \\
\hline \multirow[t]{7}{*}{$\mathrm{Na}^{+}$} & K12 & $y=933.48 \mathrm{e}^{-0.196 x}$ & 0.785 & -36.592 & 0.613 & 6.27 & 3.846 & -746 \\
\hline & M12 & $y=824.12 \mathrm{e}^{-0.146 x}$ & 0.748 & -24.064 & 0.569 & 6.27 & 3.566 & -422 \\
\hline & M14 & $y=897.8 \mathrm{e}^{-0.16 x}$ & 1.000 & -28.730 & 0.499 & 6.27 & 3.130 & -388 \\
\hline & N13 & $y=673.25 \mathrm{e}^{-0.06 x}$ & 0.617 & -8.080 & 0.506 & 6.27 & 3.174 & -112 \\
\hline & P9 & $y=571.34 \mathrm{e}^{-0.041 x}$ & 0.695 & -4.684 & 0.436 & 6.27 & 2.734 & -48 \\
\hline & $\mathrm{P} 11$ & $y=577.33 \mathrm{e}^{0.0094 x}$ & 0.640 & 1.086 & 0.619 & 6.27 & 3.881 & 23 \\
\hline & Q8 & $y=532.09 \mathrm{e}^{0.0738 x}$ & 0.887 & 7.854 & 0.466 & 6.27 & 2.922 & 92 \\
\hline \multirow[t]{7}{*}{$\mathrm{Cl}^{-}$} & K12 & $y=1389.1 \mathrm{e}^{-0.241 x}$ & 0.844 & -66.954 & 0.613 & 10.1 & 6.195 & -2198 \\
\hline & M12 & $y=1099.7 \mathrm{e}^{-0.086 x}$ & 0.843 & -18.914 & 0.569 & 10.1 & 5.744 & -534 \\
\hline & M14 & $y=1211.7 \mathrm{e}^{-0.131 x}$ & 0.663 & -31.746 & 0.499 & 10.1 & 5.042 & -690 \\
\hline & N13 & $y=989.34 \mathrm{e}^{-0.04 x}$ & 0.677 & -7.914 & 0.506 & 10.1 & 5.113 & -177 \\
\hline & P9 & $y=987.6 \mathrm{e}^{-0.149 x}$ & 0.619 & -29.430 & 0.436 & 10.1 & 4.405 & -448 \\
\hline & P11 & $y=925.22 \mathrm{e}^{-0.042 x}$ & 0.694 & -7.772 & 0.619 & 10.1 & 6.252 & -260 \\
\hline & Q8 & $y=1102.8 \mathrm{e}^{-0.092 x}$ & 0.623 & -20.292 & 0.466 & 10.1 & 4.708 & -385 \\
\hline
\end{tabular}

* 自沉积物向上扩散为正值; 自上覆水体向沉积物扩散即沉积物吸收,为负值.

\section{3 讨论}

\section{1 结冰前后盐分的扩散趋势分析}

为了准确评估 TDS 的迁移过程, 对结冰前 (2017 年 10 月) 上覆水和表层沉积物间隙水中 TDS 浓度进行 了分析. 由图 3 可知, 上覆水中 TDS 浓度的变化范围为 $989 \sim 1315 \mathrm{mg} / \mathrm{L}$, 均值为 $1173 \mathrm{mg} / \mathrm{L}$. 表层沉积物间隙 水中 TDS 浓度的变化范围为 1002 1978 mg/L, 均值为 $1415 \mathrm{mg} / \mathrm{L}$. 即表层沉积物间隙水中 TDS 浓度高于上 覆水 1.2 倍, 表明结冰前 TDS 存在从间隙水向上覆水扩散的趋势.

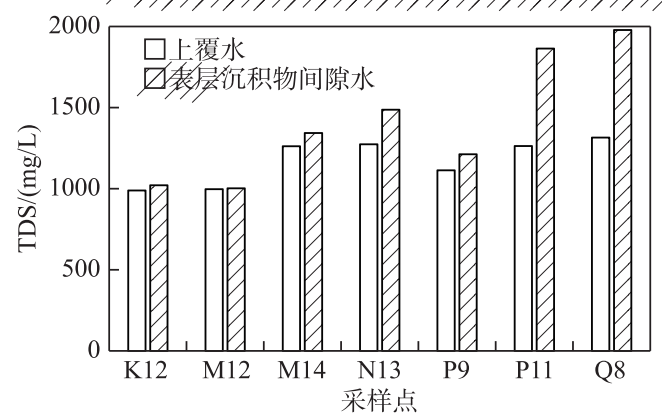

图 3 乌梁素海结冰前上覆水和表层沉积物间隙水 TDS 浓度变化

Fig.3 Changes of TDS concentration in the overlying water and surface sediments before icing in Lake Ulansuhai 
自然环境下,水体在结冰时会将盐分排人到未结冰的水体中,使盐分在冰下水体中浓缩. 湖水在结冰过 程中, 细小、平整且不含杂质的冰晶首先形成, 而后这些冰晶相互连接合并形成柔性冰. 伴随着温度的持续 降低, 柔性冰相互结合变厚, 形成坚硬冰盖. 在冰一水界面附近, 水分子在氢键作用下缔结析出, 附着在冰层 下表面冻结成冰. 同时,由于湖冰对 TDS 的排斥效应,使得 TDS 由冰体迁移至水体,致使冰一水界面处 TDS 的浓度远高于整个液相中的浓度, 在浓度差的推动下, 固液界面处的 TDS 又向液相扩散 ${ }^{[19]}$. 表明在湖泊结 冰过程中, TDS 在冰下水体中浓缩, 结冰过程有排斥 TDS 效应, 致使水体中 TDS 的浓度高于冰体中的浓度. 水体 TDS 浓度的升高导致一部分 TDS 迁移至沉积物, 致使沉积物中 TDS 浓度的升高. 与非冰封期相比, 低 温、低溶解氧浓度和冰下水的低扰动都将影响 TDS 向沉积物的迁移 ${ }^{[20]}$.

表 3 乌梁素海结冰前后各采样点的水深

Tab.3 Water depths at sampling sites before and after freezing in Lake Ulansuhai

\begin{tabular}{llllllll}
\hline & $\mathrm{K} 12$ & $\mathrm{M} 12$ & $\mathrm{M} 14$ & $\mathrm{~N} 13$ & $\mathrm{P} 9$ & $\mathrm{P} 11$ & $\mathrm{Q} 8$ \\
\hline 结冰前水深 $/ \mathrm{m}$ & 2.35 & 2.46 & 2.15 & 2.43 & 2.01 & 1.94 & 1.77 \\
结冰后水深 $/ \mathrm{m}$ & 1.79 & 1.96 & 1.60 & 2.00 & 1.55 & 1.56 & 1.32 \\
水深变化量 $/ \mathrm{m}$ & 0.56 & 0.50 & 0.55 & 0.43 & 0.46 & 0.38 & 0.45 \\
\hline
\end{tabular}

\section{2 影响因素分析}

河套灌区农田退水、上游工业废水和生活污 水通过总排干渠从湖区西北端人湖, 受芦苇区阻 碍分流, 与八排、九排等干渠污水混合叠加, 使得 盐分在乌梁素海中部湖区出现高值区, 导致 K12、 M12 和 M14 点水体的盐分浓度较高. 湖泊自身的 过滤作用使得盐分被稀释, 并沿水流方向表现出 递减的趋势, 导致 N13、P9、P11 和 Q8 点水体的盐 分浓度较低. 通过对结冰前后水深的分析 (表 3),

水深的变化量越大, 表明冰厚越深, 液态水的体积越小, 从而浓缩在冰下水中的盐分越多. K12、M12 和 M14 点水深的变化量相对较大, 从而水体的盐分浓度相对较高; N13、P9、P11 和 Q8 点水深的变化量相对较小, 从 而水体的盐分浓度相对较低. 当乌梁素海的外部污染源得到控制以后, 水体和沉积物间隙水的盐分浓度差 异将影响扩散速率和扩散方向. K12、M12 和 M14 点水一沉积物界面浓度梯度较大, 使得 $\mathrm{Na}^{+}$和 $\mathrm{Cl}^{-}$从上覆水 向间隙水扩散速率较高, 进而加快 $\mathrm{Na}^{+}$和 $\mathrm{Cl}^{-}$的沉积; N13、P9、P11 和 Q8 点水一沉积物界面浓度梯度较小, 使 得 $\mathrm{Na}^{+}$和 $\mathrm{Cl}^{-}$从上覆水向间隙水扩散速率较低, 当 $\mathrm{Na}^{+}$和 $\mathrm{Cl}^{-}$浓度对深度进行拟合的幂指数为正数时, 会出现 释放现象. 扩散通量 $F$ 与浓度梯度 $\mathrm{d} c / \mathrm{d} x$ 、孔隙度 $\varphi$ 、分子扩散系数 $D_{\mathrm{s}}$ 有关, 当 $\varphi$ 和 $D_{\mathrm{s}}$ 确定时, 水一沉积物界 面间隙水中盐分的 $\mathrm{d} c / \mathrm{d} x$ 越大, $F$ 就越高; 水一沉积物界面间隙水中盐分的 $\mathrm{d} c / \mathrm{d} x$ 越小, $F$ 就越低. 因此应关 注水体和沉积物间盐分的浓度差异.

\section{4 结论}

1) 湖泊结冰过程中, 盐分在冰下水体中浓缩, 结冰过程有排斥盐分效应, 致使水体中盐分的浓度高于冰 体中的浓度.

2) 冰封期乌梁素海水体中盐分的增加打破了盐分在水一沉积物间的动态平衡, 在此期间盐分从上覆水 体向间隙水扩散迁移,冰封期沉积物呈现为盐分的“汇”,使盐分在沉积物中汇集.

3 ) 当乌梁素海的外部污染源得到控制以后, 水体和沉积物间隙水的盐分浓度差异将影响扩散速率和扩 散方向,因此应关注水体和沉积物间盐分的浓度差异.

\section{5 参考文献}

[ 1 ] Wu Y, Shi XH, Zhao SN et al. Analysis of water chemistry characteristics and controlling factors of three typical lakes in Inner Mongolia Plateau. Journal of Eco-Environment, 2015, (7) : 1202-1208. DOI: 10.16258/2015.07.019. [吴用, 史 小红, 赵胜男等. 内蒙古高原 3 大典型湖泊水化学特征及其控制因素分析. 生态环境学报, 2015, (7): 1202-1208.]

[ 2 ] Zhou YK, Jiang JH, Huang Q et al. Analysis of water salinization process in Bohai Sea, Inner Mongolia. Journal of Arid Land Resources and Environment, 2008, 22(12) : 51-55. DOI: 10.13448/2008.12.007. [周云凯, 姜加虎, 黄群等. 内 蒙古岱海水质咸化过程分析. 干旱区资源与环境, 2008, 22(12) : 51-55.]

[ 3 ] Zhang Y. Mechanism of pollutant migration during icing process inUlansuhai and its application [Dissertation]. Hohhot: Inner Mongolia Agricultural University, 2012. [张岩. 乌梁素海结冰过程中污染物迁移机理及其应用研究 [学位论 
文]. 呼和浩特: 内蒙古农业大学, 2012.]

[ 4 ] Wang YJ, Sun ZD. Lakes in the arid areas in China. Arid Zone Research, 2007, 24(4) : 422-427.

[ 5 ] Tao XD, Shi PJ, Li MJ. Study on ecological environment rebuilding and utilization of water resources in arid area of northwest China. Arid Zone Research, 2001, 18(1) : 18-22.

[ 6 ] Lv HZ, Li CY, Shi XH et al. Simulation of the distribution of Ulansuhai pollutants in ice-water system under different conditions. J Lake Sci, 2015, 27(6): 1151-1158. DOI: 10.18307/2015.0621. [吕宏洲, 李畅游, 史小红等. 不同条件下 乌梁素海污染物在冰-水体系中分布规律的模拟. 湖泊科学, 2015, 27(6): 1151-1158.]

[ 7 ] Cui FL, Li CY, Shi XH et al. Characteristics of seasonal variation of main ions in Ulansuhai. Journal of Arid Land Resources and Environment, 2013, 27(8): 137-142. DOI: 10.13448/2013.08.013[崔凤丽, 李畅游, 史小红等. 乌梁素 海主要离子季节变化特征分析. 干旱区资源与环境, 2013, 27(8): 137-142.]

[ 8 ] Ding TM, Wang F, Yan SQ. Influence of environmental pollution on the sustainable development of fisheries in China's coastal waters and countermeasures. Journal of Fisheries Science and Technology, 2001, 28(1) : 44-48. [ 丁天明, 王飞, 严世强. 我国沿岸海域环境污染对渔业可持续发展的影响及对策探讨. 水产科技情报, 2001, 28(1): 44-48.]

[ 9 ] Yang F. Study on the characteristics of ice cover in Ulansuhai and its impact on nutrient transfer process [Dissertation]. Hohhot: Inner Mongolia Agricultural University, 2016. [ 杨芳. 乌梁素海覆冰特征及其对营养盐运移过程的影响研究 [学位论文]. 呼和浩特: 内蒙古农业大学, 2016.]

[10] Li X, Song LX, Ji DB et al. Nitrogen release characteristics at sediment-water interface of typical tributaries of the Three Gorges Reservoir during the spring sensitive period. Journal of Environmental Science, 2018, (3) : 1113-1121. DOI: 10. 13227/201707139. [李欣, 宋林旭, 纪道斌等. 春季敏感时期三峡水库典型支流沉积物-水界面氮释放特性. 环境科 学, 2018, (3): 1113-1121.]

[11] He J, Chen CY, Deng WM et al. Distribution and release characteristics of phosphorus in water-sediment inter-face of Lake Dianchi. J Lake Sci, 2015, 27(5) : 799-810. DOI: 10.18307/2015.0506. [ 何佳, 陈春瑜, 邓伟明等. 滇池水-沉积物 界面磷形态分布及潜在释放特征. 湖泊科学, 2015, 27(5) : 799-810.]

[12] Liu J. Research on dissolved inorganic nitrogen exchange at the sediment-water interface of the Yangtze estuarine tidalflats [Dissertation]. Shanghai : East China Normal University, 2006. [刘杰. 长江口潮滩无机氮界面交换研究 [学位论文]. 上海: 华东师范大学, 2006.]

[13] Jiang ZJ, Fang JG, Mao YZ et al. Diffusion fluxes of nitrogen and phosphorus nutrients at the sediment-water interface in the aquaculture waters of Nansha Harbor, Ningbo, China. Journal of Agro-Environment Science, 2010, 29 (12) : 24132419. [蒋增杰, 方建光, 毛玉泽等. 宁波南沙港养殖水域沉积物-水界面氮磷营养盐的扩散通量. 农业环境科学学 报, 2010, 29(12): 2413-2419.]

[14] Martinova MV. Nitrogen and phosphor compounds in bottom sediments : mechanisms of accumulation, transformation and release. Hydrobiologia , 1993, 252(1): 1-22.

[15] Urban NR, Dinkel C, Wehrli B. Solute transfer across the sediment surface of a eutrophic lake: I. Pore water profiles from dialysis samplers. Aquatic Sciences, 1997, 59(1): 1-25.

[16] Borowski WS, Paull CK, Ussler WI. Marine pore-water sulfate profiles indicate in situ methane flux from underlying gas hydrate. Geology, 1996, 24(7): 655-658.

[17] Li YH, Gregory S. Diffusion of ions in sea water and in deep-sea sediments. Geochimica et Cosmochimica Acta, 1974, 38 (5) : 703-714.

[18] Li CY, Shi XH eds. Study on environmental geochemical characteristics of sediments in Ulansuhai Lake. Beijing: Science Press, 2014: 44. [李畅游, 史小红. 乌梁素海沉积物环境地球化学特征研究. 北京: 科学出版社, 2014: 44.]

[19] Li CY, Shi XH, Zhao SN eds. Study on ice environmental characteristics and material migration of Ulansuhai Lake. Beijing: Science Press, 2016: 90. [李畅游, 史小红, 赵胜男. 乌梁素海湖冰环境特征及物质迁移规律研究. 北京: 科 学出版社, 2016: 90.]

[20] Lu P, Li Z, Cheng B et al. Sea ice surface features in Arctic summer 2008: Aerial observations. Remote Sensing of Envieonment, 2010, 114: 693-699. 